\title{
High flow nasal cannula oxygen therapy versus
} non-invasive ventilation for chronic obstructive pulmonary disease with acute-moderate

\section{hypercapnic respiratory failure: an observational cohort study}

This article was published in the following Dove Press journal: International Journal of Chronic Obstructive Pulmonary Disease

\author{
Jiayan Sun' \\ Yujie $\mathrm{Li}^{1}$ \\ Bingyu Ling' \\ Qingcheng Zhu' \\ Yingying $\mathrm{Hu}^{2}$ \\ Dingyu Tan' \\ Ping Geng' \\ Jun $\mathrm{Xu}^{3}$
}

'Department of Emergency, Clinical Medical College, Yangzhou University, Northern Jiangsu People's Hospital, Yangzhou, People's Republic of China; ${ }^{2}$ Department of Emergency, Peking Union Medical College Hospital, Chinese Academy of Medical Sciences, Beijing, People's Republic of China; ${ }^{3}$ Department of Emergency, The First Affiliated Hospital, and College of Clinical Medicine of Henan University of Science and Technology, Luoyang, People's Republic of China

Correspondence: Dingyu Tan Department of Emergency, Clinical Medical College, Yangzhou University, Northern Jiangsu People's Hospital, No.

98, Nantong West Road, Guangling District, Jiangsu Province, Yangzhou 22500I, People's Republic of China

Tel +86I805106 I672

Email webtan1981@gmail.com
Background: High-flow nasal cannula (HFNC) oxygen therapy in acute hypoxic respiratory failure is becoming increasingly popular. However, evidence to support the use of HFNC in acute respiratory failure (ARF) with hypercapnia is limited.

Methods: Chronic obstructive pulmonary disease (COPD) patients with moderate hypercapnic ARF (arterial blood gas $\mathrm{pH} 7.25-7.35, \mathrm{PaCO}_{2}>50 \mathrm{mmHg}$ ) who received HFNC or non-invasive ventilation (NIV) in the intensive care uint from April 2016 to March 2018 were analyzed retrospectively. The endpoint was treatment failure, defined as either invasive ventilation, or a switch to the other study treatment (NIV for patients in the NFNC group, and vice-versa), and 28-day mortality.

Results: Eighty-two COPD patients (39 in the HFNC group and 43 in the NIV group) were enrolled in this study. The mean age was $71.8 \pm 8.2$ and 54 patients $(65.9 \%)$ were male. The treatment failed in 11 out of 39 patients with HFNC $(28.2 \%)$ and in 17 of 43 patients with NIV $(39.5 \%)(P=0.268)$. No significant differences were found for 28 -day mortality $(15.4 \%$ in the HFNC group and $14 \%$ in the NIV group, $P=0.824)$. During the first $24 \mathrm{hrs}$ of treatment, the number of nursing airway care interventions in the HFNC group was significantly less than in the NIV group, while the duration of device application was significantly longer in the HFNC group (all $P<0.05$ ). Skin breakdown was significantly more common in the NIV group $(20.9 \%$ vs $5.1 \%, P<0.05)$.

Conclusion: Among COPD patients with moderate hypercarbic ARF, the use of HFNC compared with NIV did not result in increased rates of treatment failure, while there were fewer nursing interventions and skin breakdown episodes reported in the HFNC group.

Keywords: chronic obstructive pulmonary diseases, respiratory failure, high-flow nasal cannula, non-invasive ventilation, cohort study

\section{Introduction}

Chronic obstructive pulmonary disease (COPD) remains a common cause of morbidity and mortality worldwide. Acute respiratory failure (ARF) with hypercapnia is a common complication of COPD, and is associated with an increased need for respiratory support and a greater risk of death. ${ }^{1}$ Non-invasive ventilation (NIV) is recommended as the gold-standard therapy for COPD patients complicated 
by hypercapnic ARF. $^{2}$ However, NIV may not be well tolerated, and about $25 \%$ of subjects have contraindications to NIV. ${ }^{3}$

High-flow nasal cannula (HFNC) oxygen therapy is an emerging respiratory support system, which is better tolerated than NIV. ${ }^{4}$ HFNC has been evaluated in recent years as an alternative to NIV in acute hypoxaemic respiratory failure or post-extubation. ${ }^{5-7}$ HFNC appears to improve exercise tolerance and reduce partial pressure of carbon dioxide $\left(\mathrm{PaCO}_{2}\right)$, respiratory rate and work of breathing in stable COPD patients. ${ }^{8}$ However, the role of HFNC in hypercapnic ARF has not been widely studied. HFNC has been reported to successfully manage hypercapnic ARF in COPD patients who decline NIV in case reports. ${ }^{10,11}$ In two small studies, $\mathrm{HFNC}$ decreased $\mathrm{PaCO}_{2}$ compared with oxygen therapy via nasal prongs in COPD patients with hypercapnic ARF. ${ }^{12,13}$

We hypothesized that HFNC and NIV had similar therapeutic effects on COPD patients with moderate hypercapnic ARF. This observational study was conducted to compare the effectiveness of HFNC and NIV for these patients.

\section{Materials and methods}

\section{Study design and ethical approval}

Between April 2016 and March 2018, discharge reports from all COPD patients admitted to our 15-bed emergency intensive care unit (ICU) in a tertiary teaching university hospital were retrospectively reviewed. The conduct of this study was in accordance with the ethical principles of the Declaration of Helsinki. This study was approved by the Institutional Ethics Committee of Northern Jiangsu People's Hospital (No. 2,017,053), and given its purely observational design and the routine use of HFNC and NIV in our unit, informed consent was waived. Patient information was de-identified and anonymized before analysis.

\section{Screening of patients}

We screened patients who received a principal discharge diagnosis of acute exacerbation of COPD, or a principal diagnosis of ARF when accompanied by a secondary diagnosis of COPD. COPD was diagnosed on the basis of the clinical history, physical examination, chest radiograph and available lung function tests. General indications for NIV or HFNC when treating COPD in our uint include respiratory acidosis ( $\mathrm{pH} \leq 7.35$ and $\mathrm{PaCO}_{2} \geq 50 \mathrm{mmHg}$ ), an exacerbation of dyspnea with evidence of accessary respiratory muscle use, and persistent hypoxemia despite oxygen therapy. ${ }^{14}$ Among those COPD patients who were treated with HFNC (Optiflow $^{\mathrm{TM}}$, Fisher\&Paykel Healthcare) or NIV (BiPap Vision or PHILIPS V60) within four hours of admission, patiens meeting criteria for moderate hypercapnic ARF were included. Moderate hypercapnic ARF was defined as respiratory acidosis characterized by a $\mathrm{pH}$ range from 7.25 to 7.35 and a $\mathrm{PaCO}_{2}$ $\geq 50 \mathrm{mmHg}$, accompanied by a partial arterial oxygen tension $\left(\mathrm{PaO}_{2}\right)$ below $45 \mathrm{mmHg}$ on room air.

Exclusion criteria were: severe respiratory failure requiring immediate tracheal intubation (respiratory frequency $\geq 40$ times/min, severe hypoxia, severe respiratory acidosis with a pH $<7.25$, Glasgow score <8), a contraindication to NIV (oral and facial trauma, excessive phlegm with poor expectoration ability, hemodynamic instability), no treatment with systemic corticosteroids or short-acting bronchodilators within the first two days of the hospital stay, patients with poor short term prognosis (very high risk of death within seven days or receiving palliative care), other organ failure, tracheostomy, and loss to follow-up after hospital discharge.

\section{Classification of patients}

Patients were classified into two groups according to the time from the admission to the ICU and the start of firstline ventilatory support including HFNC or NIV. All patients in whom HFNC was started within the first four hous from admission were included in the HFNC group, if they received at least four hours of HFNC within the first $24 \mathrm{hrs}$. Those who were treated with NIV within the first four hours of admission were included in the NIV group, if they received at least four hours of NIV within the first 24 hrs. Conventional oxygen therapy via nasal prongs was used between episodes of ventilatory support. A patient's group classification would not change if the patient received another ventilatory support device or invasive mechanical ventilation later in their admission. For example, patients initially treated with NIV for five hours and then received HFNC or invasive mechanical ventilation as rescue therapy, remained classified in the NIV group. Each patient was classified by consensus of three senior intensivists (PG, QZ, and DT) blinded to outcomes up to full agreement.

The indications for intubation and invasive mechanical ventilation in patients with COPD in our uint were: $\mathrm{pH}<7.20$ with progressively increasing $\mathrm{PaCO}_{2}$, 
uncontrolled hypoxia defined by as a $\mathrm{PaO}_{2}<50 \mathrm{mmHg}$ despite ample oxygen, serious disturbances of consciousness (coma, lethargy or delirium), cardiac arrest, or respiratory rate $<8$ or $>40$ breaths per minute. ${ }^{15,16}$

\section{Data collection}

For eligible patients, personal characteristics, relevant comorbidities, pre-admission COPD duration (in years) and medications, available pulmonary function tests including forced expiratory volume in one second $\left(\mathrm{FEV}_{1}\right)$ and $\mathrm{FEV}_{1} /$ forced vital capacity $(\mathrm{FVC})$, imaging studies, severity scores including the acute physiological and chronic health status score II (APACHE II), and the Simplified Acute Physiology Score II (SAPS II), and the time of ICU admission were recorded. Physiological data including arterial blood gas analysis and vital signs such as heart rate, respiratory rate, blood pressure, and pulse oxygen saturation at ICU admission were also collected.

We collected the initial settings of NIV or HFNC, daily total respiratory support time, respiratory support switch details (changes from NIV to HFNC or from HFNC to NIV, or a change to invasive ventilation, including specific time and reasons). In addition, respiratory rates and arterial blood gas analysis $24 \mathrm{hrs}$ after initial respiratory support were recorded, as well as the daily total number of nursing airway care interventions (such as correcting unplanned device displacement, assisting in spitting, eating and so on), nasal facial skin breakdown, and total hospital and ICU length of stay were recorded.

\section{Outcomes}

The primary outcome was treatment failure, defined as invasive ventilation, or a switch in ventilation treamtment. The secondary outcomes were 28-day mortality, the duration of device application the number of nursing airway care interventions within the first $24 \mathrm{hrs,}$, and the incidence of nasal facial skin breakdown after total duration of respiratory support. In addition, we assessed the respiratory rate and $\mathrm{PaO}_{2} /$ fraction of inspired oxygen $\left(\mathrm{FiO}_{2}\right)$ ratio after $24 \mathrm{hrs}$ of treatment, as well as the number of days of respiratory support, and total ICU and hospital length of stay.

\section{Statistical analysis}

We performed all data analysis using SPSS 20.0 (SPSS Inc, Chicago, Ill, USA). The consistency test of normal distribution for measurement data was carried out by Single Kolmogorov-Smirnov tests. Normally distribute data was reported using a mean with SDs, while skewed distribution data was reported using a median (quartile). The two sample independent $t$ test or Mann-Whitney $\mathrm{U}$ test was used to compare measurement data. Numeric data was reported by percentage (\%), and such data were analyzed using $\chi^{2}$ tests. We used Kaplan-Meier method to draw the cumulative failure and survival rates. These curves were then analyzed by $\log$ Rank tests. A $P$-value $<0.05$ was considered to be statistically significant.

\section{Results \\ Patient characteristics}

Among 277 COPD patients who were admitted to our unit during the study period, 142 cases were consistent with the criteria of blood gas analysis. Among these 142 patients, 60 of them were excluded (18 patients had invasive ventilation, five patients had contraindications to NIV, six patients had advanced tumors, 12 patients had other organ failures, three patients had tracheostomies, eight patients had no discharge follow-up, and eight patients received HFNC or NIV for preoxygenation before tracheal intubation or as remedial measure four hours later). 82 patients were finally selected, including 39 in the HFNC group and 43 in the NIV group (Figure 1). The mean age of the patients was $71.8 \pm 8.2$ years and the majority were male (65.9\%). $51(61.4 \%)$ out of 83 patients were either current or ex-smokers, and hypertension was the most common comorbidity, observed in $56.1 \%$ of patients.

The median COPD history of the enrolled patients was 8 years. The median time from the start of the current acute episode to the admission to the ICU was 5 (3-7) days, and $41.4 \%$ of them were admitted to the ICU due to respiratory failure caused by pneumonia. On admission to ICU, patients had a mean SAPS-II and APACHE-II scores of $33.4 \pm 6.1$ and $17.8 \pm 3.1$, respectively. The initial respiratory rate was $27.5 \pm 3.5$ breaths $/ \mathrm{min}$, while the arterial $\mathrm{PH}$ was 7.31(7.29-7.33), and the median $\mathrm{PaCO}_{2}$ was 58 (54-62) $\mathrm{mm} \mathrm{Hg}$. There was no statistical difference between the two groups based on age, comorbidities, COPD medications, lung function $\left(\mathrm{FEV}_{1}\right.$ and $\mathrm{FEV}_{1}$ (FVC), APACHE II score, SAPS II score, vital signs or blood gas analysis on admission to the ICU (Table 1).

\section{Hospital course and outcomes}

The initial $\mathrm{FiO}_{2}$ in the HFNC group was $0.3(0.2-0.4)$, and the gas flow rate was $50(40-50) \mathrm{L} / \mathrm{min}$. While the initial $\mathrm{FiO}_{2}$ in the NIV group was $0.4(0.3-0.6)$, inspiratory 


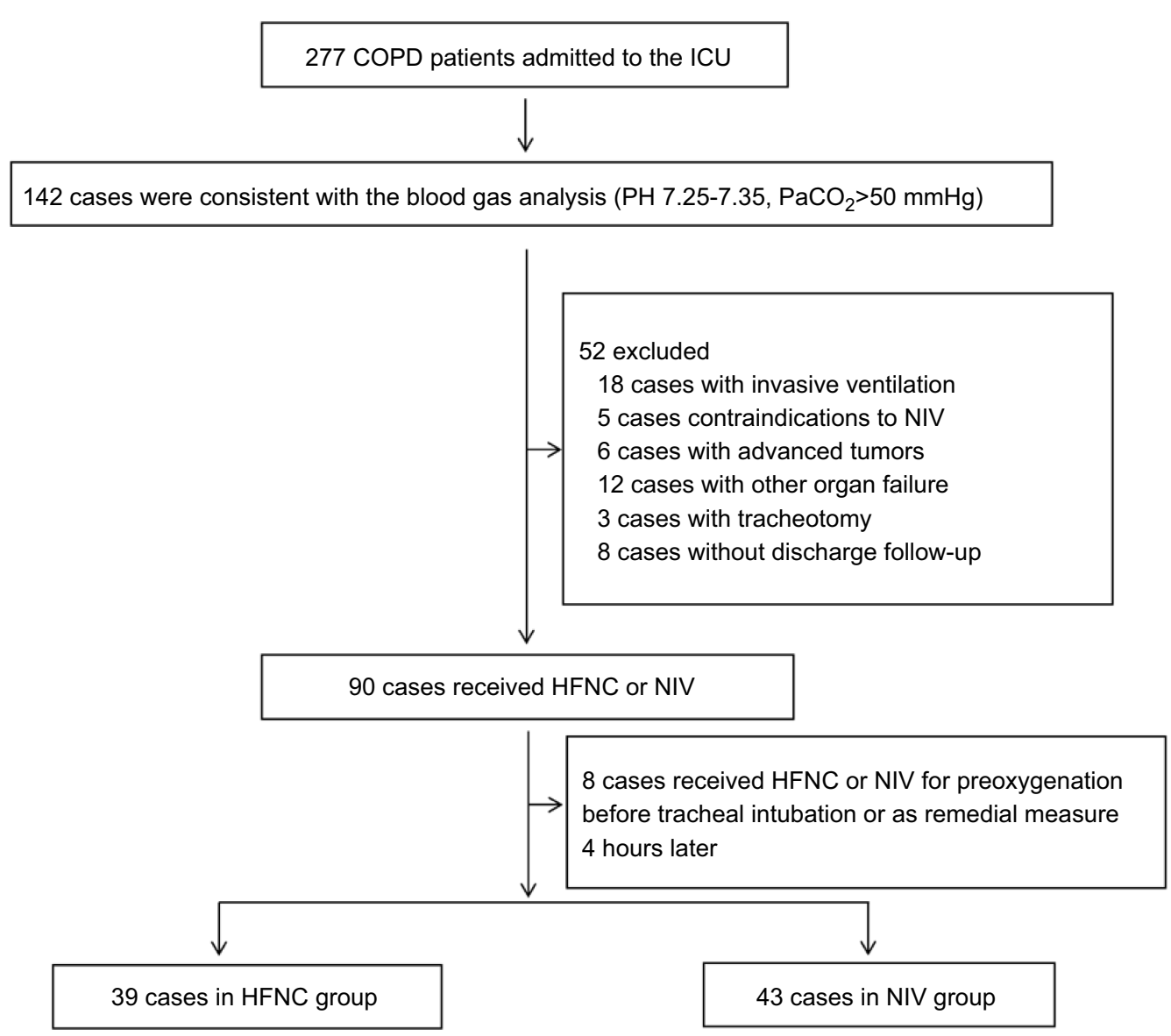

Figure I Flow chart of patient enrollment.

Abbreviations: COPD, Chronic obstructive pulmonary disease; ICU, Intensive care unit; HFNC, High flow nasal cannula oxygen therapy; NIV, Non-invasive ventilation.

airway pressure was $10(8-12) \mathrm{cmH} 2 \mathrm{O}$, and expiratory airway pressure was $4(4-5) \mathrm{cmH} 2 \mathrm{O}$. Mean expiratory tidal volume during the first $24 \mathrm{hrs}$ of NIV treatment was $5.4 \pm 2.4 \mathrm{ml} / \mathrm{kg}$ of predicted body weight.

Overall treatment failure rate in this study was $34.1 \%$ (28 of 82 patients), and total mortality at day 28 was $14.6 \%$ (12 of 82 patients). Treatment failed in 11 of 39 patients with HFNC, in which eight cases received invasive ventilation and three cases switched to NIV. 17 of 43 patients in the NIV group had treatment failure, in which nine cases received invasive ventilation and eight cases later received HFNC. The HFNC group had a treatment failure rate of $28.2 \%$, which was lower than that of the NIV group (39.5\%). However, Kaplan-Meier curve analysis showed no significant difference between the two groups (Log Rank test 1.228, $P=0.268$, Figure 2). There were no differences between the two groups in intubation rate or treatment switch. The 28-day mortality in the HFNC group was $15.4 \%$, which was not ststistically different from the $14 \%$ in the NIV group (Log Rank test $0.049, P=0.824$, Figure 3) (Table 2).
The number of airway care interventions within the first $24 \mathrm{hrs}$ was significantly lower in the HFNC group than in the NIV group [5 (4-7) vs 8 (7-10)], whereas the duration of device application within the first $24 \mathrm{hrs}$ was significantly longer in the HFNC group than in the NIV group [16.0 \pm 3.9 hrs vs $11.7 \pm 3.1 \mathrm{hrs}$ ( all $P<0.001$, Table 2 ). The incidence of nasal facial skin breakdown in the NIV group was $20.9 \%$, significantly higher than that of the HFNC group $(5.1 \%, P<0.05)$. There were no significant differences in respiratory rate, $\mathrm{PaCO}_{2}$, and $\mathrm{PaO}_{2} / \mathrm{FiO}_{2}$ ratio $24 \mathrm{hrs}$ after treatment between the two groups, as well as in the total days of respiratory support, ICU or hospital total length of stay.

\section{Treatment failure analysis}

Analysis of the reasons of treatment failure in the two groups showed that the intolerance rate of NIV was significantly higher than that of the HFNC (47.1-9\%, $P=0.026$, Table 3$)$. However, there was no difference between the two groups regarding respiratory distress, hypoxemia and carbon dioxide retention. One patient's intolerance in the HFNC group was 
Table I Baseline characteristics of enrolled patients

\begin{tabular}{|c|c|c|c|c|}
\hline Characteristics & Total $(n=82)$ & HFNC(n=39) & $\operatorname{NIV}(n=43)$ & P-value \\
\hline Male, $n(\%)$ & $54(65.9)$ & $24(6 \mid .5)$ & $30(69.8)$ & 0.645 \\
\hline Age, years & $71.8 \pm 8.2$ & $73.2 \pm 9.0$ & $70.4 \pm 7.4$ & 0.130 \\
\hline History of COPD, years & $8(6-I I)$ & $9(6-12)$ & $8(6-10)$ & 0.216 \\
\hline \multicolumn{5}{|l|}{ Comorbidities, n(\%) } \\
\hline Diabetes Mellitus & $22(26.8)$ & $9(23.1)$ & $13(30.2)$ & 0.824 \\
\hline Hypertension & $46(56.1)$ & $21(53.8)$ & $25(58.1)$ & 0.696 \\
\hline Coronary artery disease & $36(43.9)$ & $17(43.6)$ & $19(44.2)$ & 1.0 \\
\hline Chronic liver disease & $7(8.5)$ & $4(10.3)$ & $3(7.0)$ & 0.703 \\
\hline Chronic kidney disease & $22(26.8)$ & $9(23.1)$ & $13(30.2)$ & 0.618 \\
\hline Cerebrovascular disease & $13(15.9)$ & $7(17.9)$ & $6(14.0)$ & 0.764 \\
\hline Malignancy & $9(11.0)$ & $4(10.3)$ & $5(11.6)$ & 1.0 \\
\hline \multicolumn{5}{|l|}{ Medication before an exacerbation, $n(\%)$} \\
\hline Inhaled corticosteroids & $27(32.9)$ & $12(30.8)$ & $15(34.9)$ & 0.815 \\
\hline Beta adrenoceptor agonist & $33(40.2)$ & $16(41.0)$ & $17(39.5)$ & 1.0 \\
\hline Anticholinergics & $16(19.5)$ & $8(20.5)$ & $8(18.6)$ & 1.0 \\
\hline \multicolumn{5}{|l|}{ Lung function test before an exacerbation $(n=49)^{*}$} \\
\hline $\mathrm{FEV}_{1}, \%$ & $46.8 \pm 15.2$ & $47.7 \pm 15.9$ & $45.9 \pm 14.9$ & 0.682 \\
\hline $\mathrm{FEV}_{\mathrm{I}} / \mathrm{FVC}, \%$ & $45.5 \pm 11.3$ & $46.0 \pm 11.1$ & $45.2 \pm 11.6$ & 0.806 \\
\hline $\begin{array}{l}\text { Mean length from the acute attack to the admission to the ICU, days } \\
\text { On admission to ICU }\end{array}$ & $5(3-7)$ & $4(2-6)$ & $5(3-7)$ & 0.224 \\
\hline APACHE II score & $17.8 \pm 3.1$ & $18.4 \pm 2.7$ & $17.3 \pm 3.4$ & 0.126 \\
\hline SAPS II score & $33.4 \pm 6.1$ & $34.8 \pm 5.9$ & $32.2 \pm 6.0$ & 0.053 \\
\hline Arterial $\mathrm{pH}$ & $7.31(7.29-7.33)$ & $7.31(7.29-7.33)$ & $7.30(7.28-7.32)$ & 0.106 \\
\hline Oxygen saturation, $\%$ & $89(86-91)$ & $89(84-91)$ & $89(87-90)$ & 0.514 \\
\hline $\mathrm{PaCO}_{2}, \mathrm{~mm} \mathrm{Hg}$ & $58(54-62)$ & $56(53-62)$ & $59(55-62)$ & 0.088 \\
\hline Mean arterial pressure, $\mathrm{mm} \mathrm{Hg}$ & $89.2 \pm 6.7$ & $88.3 \pm 5.9$ & $90.0 \pm 7.4$ & 0.251 \\
\hline Heart rate, beats/min & $103.1 \pm 10.9$ & $102.2 \pm 10.7$ & $103.9 \pm 11.2$ & 0.491 \\
\hline Respiratory frequency,/min & $27.5 \pm 3.5$ & $28.1 \pm 3.3$ & $27.0 \pm 3.5$ & 0.142 \\
\hline $\mathrm{PaO}_{2} / \mathrm{FiO}_{2}, \mathrm{~mm} \mathrm{Hg}$ & $139.2 \pm 6.7$ & $138.2 \pm 6.6$ & $140.1 \pm 6.6$ & 0.189 \\
\hline With pneumonia, n(\%) & $34(4 \mid .4)$ & $14(35.9)$ & $20(46.5)$ & 0.375 \\
\hline
\end{tabular}

Notes: *23 cases in the HFNC group and 26 cases in the NIV group. Data are shown as mean \pm standard deviation, number (\%) patients, or median (interquartile range). Abbreviations: HFNC, High flow nasal cannula oxygen therapy; NIV, Non-invasive ventilation; COPD, Chronic obstructive pulmonary disease; ICU, intensive care unit; APACHE II, Acute Physiology and Chronic Health Evaluation II; SAPS II, Simplified acute physiology score II; $\mathrm{PaCO}_{2}$, arterial carbon dioxide partial pressure; PaO ${ }_{2}$, arterial oxygen partial pressure.

due to "too strong airflow". The causes of eight intolerances in the NIV group were claustrophobia( $\mathrm{n}=2)$, breathlessness $(n=2)$, airflow or pressure too strong $(n=2)$, coughing $(n=1)$, and headache $(n=1)$. Eleven cases $(64.7 \%)$ of treatment failure in the NIV group were in COPD patients with pneumonia, and there was no significant difference compared to the HFNC group (6 cases, 54.5\%).

\section{Discussion}

In this study, we investigated the effectiveness of HFNC in COPD patients with moderate hypercapnic ARF who were admitted to the ICU. We demonstrated that HFNC and NIV had similar treatment failure rates and 28-day mortality, however, HFNC was associatied with better tolerance, less airway care interventions and less incidence of skin breakdown compared to NIV.

A number of studies have shown that NIV can decrease $\mathrm{PaCO}_{2}$, alleviate respiratory distress, reduce endotracheal intubation rate, reduce length of hospital stay and mortality in patients with exacerbations of COPD. ${ }^{17-19}$ NIV is now a first-line intervention to manage respiratory failure secondary to COPD. However, NIV intolerance is a frequent occurance and increases NIV failure rates, intubation rates and overall mortality. ${ }^{20} \mathrm{HFNC}$ is a novel means of oxygen therapy with a favourable tolerance profile. However, many studies on HFNC for ARF have excluded patients with hypercapnia. ${ }^{21}$ In theory, HFNC is suitable for COPD patients, because it can provide high 


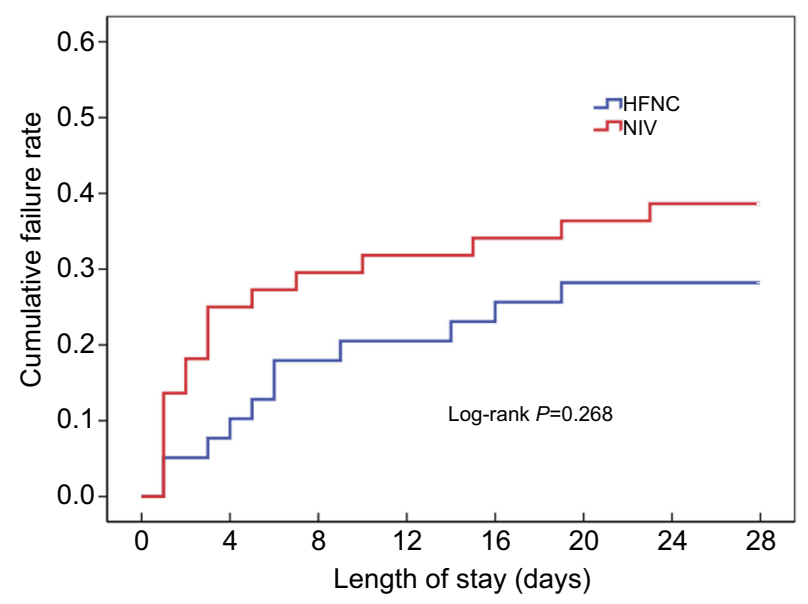

Figure 2 Kaplan-Meier curve analysis for cumulative failure rate. Abbreviations: HFNC, High flow nasal cannula oxygen therapy; NIV, Non-invasive ventilation.

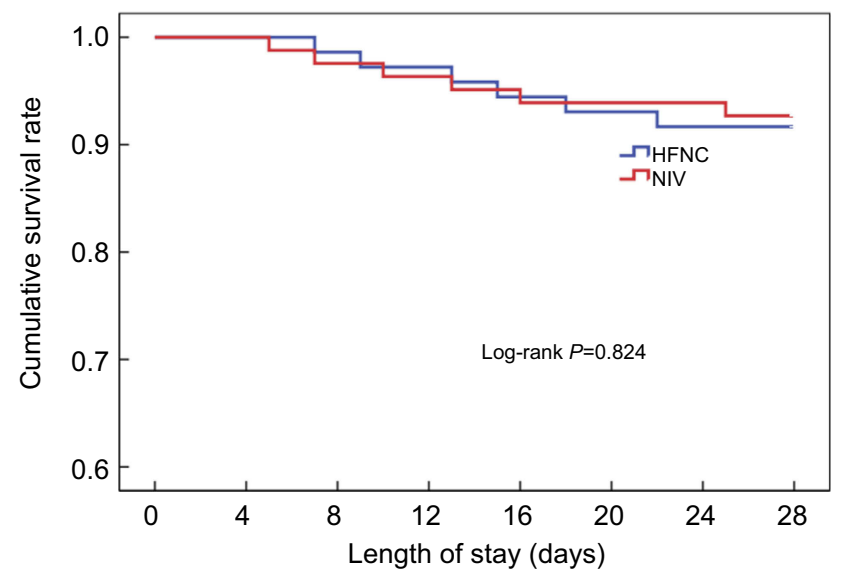

Figure 3 Kaplan-Meier curve analysis for cumulative survival rate. Abbreviations: HFNC, High flow nasal cannula oxygen therapy; NIV, Non-invasive ventilation.

airflow but at relatively lower $\mathrm{FiO}_{2}$ levels, which can create a small positive mean airway pressure, relieve respiratory distress and reduce work of breathing. The use of HFNC in stable COPD patients has been shown to reduce $\mathrm{PaCO}_{2}$, increase tidal volume, decrease minute ventilation and respiratory rate. ${ }^{22}$

Evidence to support the use of HFNC for hypercapnic ARF is limited to case reports and small studies. Compared with standard nasal prongs, short-term use of HFNC $(35 \mathrm{~L} / \mathrm{min})$ can reduce the $\mathrm{PaCO}_{2}$ by $1.4 \mathrm{mmHg}$ and the respiratory rate by 2 times $/ \mathrm{min}^{12}$ In two case reports of five COPD patients with hypercapnic ARF who declined NIV or had contraindications to NIV, HFNC significantly ameliorated respiratory acidosis, avoiding endotracheal intubation and NIV. ${ }^{10,11}$ In a retrospective study of 33 ARF patients with hypercapnia, compared with conventional oxygen therapy, HFNC decreased $\mathrm{PaCO}_{2}$ by $4.2 \pm 5.5$ and $3.7 \pm 10.8 \mathrm{mmHg}$ in one and $24 \mathrm{hrs}$ respectively, resulting in significant improvement in hypercapnia. ${ }^{13}$

There are few studies on the mechanisms of HFNC for the treatment of COPD. Fricke et al reported that HFNC could improve alveolar ventilation and reduce $\mathrm{PaCO}_{2}$ of patients with COPD through clearance of anatomical dead space. ${ }^{23}$ HFNC can continually flush out carbon dioxide from the upper airway (washout of nasopharyngeal dead space), reduce dead space and permit a more effective alveolar ventilation. HFNC also improves gas exchange and oxygenation in a flow dependent manner. HFNC forms low-level positive airway pressure $\left(1.5-7 \mathrm{cmH}_{2} \mathrm{O}\right)$ through the resistance of the nasopharynx and airway to high-flow gas. Parke et al observed that the mean airway pressure during HFNC increased as flow increased, with the mean airway pressure increasing by 0.69 $\mathrm{cmH}_{2} \mathrm{O}$ in patients with nose breathing and by $0.35 \mathrm{cmH}_{2} \mathrm{O}$ in patients with open mouth breathing when the flow rate increased by $10 \mathrm{~L} / \mathrm{min}^{24}$ In addition, the size of patients' nares relative to the nasal cannula can vary the airway pressure generated by the HFNC. ${ }^{25,26}$ Nevertheless, low-level positive airway pressure can improve oxygenation, resist endogenous positive end expiratory pressure and reduce work of breathing of patients with COPD.

To the best of our knowledge, no randomized controlled trials comparing HFNC and NIV for COPD patients with ARF have been published. An observational trial showed that there was no difference in intubation rates or 30-day mortality between HFNC and NIV for patients with acute exacerbations of COPD with moderate hypercapnic $\mathrm{ARF}^{27}$ The $\mathrm{pH}, \mathrm{PaO}_{2}$ and $\mathrm{PaCO}_{2}$ six hours and $24 \mathrm{hrs}$ after treatment between HFNC and NIV were also similar. Our findings are consistent with this study, and showed that HFNC can significantly improve carbon dioxide retention and hypoxemia, with good efficacy and safety relative to NIV.

Although NIV plays an important role in the treatment of COPD, up to $15-25 \%$ patients have a contraindication to NIV or intolerance due to various reasons, such as eye irritation, skin damage, diet or expectoration interruption, or claustrophobia. The duration with respiratory support between HFNC group and NIV group did not differ in the study of Lee et $\mathrm{al}^{27}$, suggesting that HFNC and NIV were similar in the degree of comfort. However, our study showed that the respiratory support duration of HFNC group was significantly longer than the NIV group in the first $24 \mathrm{hrs}$ of admission, and this may be primarily due to 
Table 2 Outcomes between the HFNC and NIV groups

\begin{tabular}{|c|c|c|c|}
\hline Outcomes & $\begin{array}{l}\text { HFNC } \\
(n=39)\end{array}$ & $\begin{array}{l}\text { NIV } \\
(n=43)\end{array}$ & $P$-value \\
\hline Treatment failure, $n(\%)$ & II (28.2) & $17(39.5)$ & 0.268 \\
\hline Invasive ventilation, $\mathrm{n}(\%)$ & $8(20.5)$ & $9(20.9)$ & 1.0 \\
\hline Treatment switch, n(\%) & $3(7.7)$ & $8(18.6)$ & 0.148 \\
\hline 28-day mortality, n(\%) & $6(15.4)$ & $6(14.0)$ & 0.824 \\
\hline Airway care interventions,/day* & $5(4-7)$ & $8(7-10)$ & $<0.001$ \\
\hline $\begin{array}{l}\text { Duration of device application, } \\
\text { hours* }\end{array}$ & $16.0 \pm 3.9$ & $11.7 \pm 3.1$ & $<0.001$ \\
\hline Respiratory frequency,/min ${ }^{\#}$ & $22.3 \pm 3.1$ & $23.5 \pm 2.9$ & 0.064 \\
\hline $\mathrm{PaCO}_{2}, \mathrm{~mm} \mathrm{Hg}^{\#}$ & $5 I(48-56)$ & $49(46-52)$ & 0.078 \\
\hline $\mathrm{PaO}_{2} / \mathrm{FiO}_{2}, \mathrm{~mm} \mathrm{Hg} \#$ & $\begin{array}{l}179 \\
(172-192)\end{array}$ & $\begin{array}{l}187 \\
(174-207)\end{array}$ & 0.083 \\
\hline $\begin{array}{l}\text { Respiratory support duration, } \\
\text { days }\end{array}$ & $5(4-7)$ & $6(5-8)$ & 0.148 \\
\hline $\begin{array}{l}\text { Nasal facial skin breakdown } \\
\text { after treatment, } n(\%)\end{array}$ & $2(5.1)$ & $9(20.9)$ & 0.036 \\
\hline Length of stay in ICU, days & $7(6-8)$ & $8(6-10)$ & 0.149 \\
\hline Length of stay in hospital, days & $9(7-11)$ & $10(7-12)$ & 0.207 \\
\hline
\end{tabular}

Notes: *Within the first $24 \mathrm{hrs}$ after enrollment; \#after $24 \mathrm{hrs}$ after enrollment. Data are shown as mean \pm standard deviation, number (\%) patients, or median (interquartile range).

Abbreviations: HFNC, High flow nasal cannula oxygen therapy; NIV, Non-invasive ventilation; $\mathrm{PaCO}_{2}$, arterial carbon dioxide partial pressure; $\mathrm{PaO}_{2}$, arterial oxygen partial pressure; ICU, intensive care unit.

Table 3 Analysis of treatment failure in the HFNC and NIV groups

\begin{tabular}{|c|c|c|c|}
\hline & $\begin{array}{l}\text { HFNC } \\
(n=I I)\end{array}$ & $\begin{array}{l}\text { NIV } \\
(n=\mid 7)\end{array}$ & $P$-value \\
\hline Treatment intolerance & $\mathrm{I}(9.0)$ & $8(47.1)$ & 0.026 \\
\hline $\begin{array}{l}\text { Aggravation of respiratory } \\
\text { distress }\end{array}$ & $4(36.4)$ & $3(17.6)$ & 0.381 \\
\hline Aggravation of hypoxemia & $2(18.2)$ & $\mathrm{I}(5.9)$ & 0.543 \\
\hline $\begin{array}{l}\text { Aggravation of carbon dioxide } \\
\text { retention }\end{array}$ & $4(36.4)$ & $5(29.4)$ & 1.0 \\
\hline
\end{tabular}

Note: Data are shown as a number (\%) of patients.

Abbreviations: HFNC, High flow nasal cannula oxygen therapy; NIV, Non-invasive ventilation.

the better tolerance of HFNC. Analysis of treatment failure also showed that the tolerance of HFNC was significantly better than for NIV, and intolerance was an important reason for the failure of NIV.

HFNC can provide a flow rate up to $60 \mathrm{~L} / \mathrm{min}$ in adults, as well as adequate heating and humidification help to increase the humidity of the airway, maintain mucosal function, promote secretion clearance, avoid epithelial injury and improve patient comfort. ${ }^{28}$ Nasal and facial skin breakdown caused by long-time NIV therapy is relatively common and can also increase NIV intolerance. Skin breakdown due to HFNC is rare, however, patients can breathe freely without claustrophobia, which effectively reduces the occurrence of intolerance. Patients with poor NIV tolerance often take off their mask or interrupt respiratory support because of claustrophobia, expectoration, drinking or diet, which significantly increases the need for nursing airway care interventions. Due to its unique design, HFNC rarely has treatment interruptions and doesn't affect communication, drinking or diet.

There are some limitations to this study. First, in this retrospective study, the decision to start with NIV or NHFC was made on a clinical basis, which makes it susceptible to selection bias. For COPD patients with moderate hypercarbic ARF in our unit, both HFNC and NIV were the firstline choice for respiratory support, which could reduce selection bias for other respiratory support devices. Still, there were no statistical differences in the baseline characteristics between the HFNC and NIV groups, indicating that the two groups were comparable. Second, because the sample size is relatively small, the risk factors for treatment failure of HFNC were not analyzed. It was reported that the failure of HFNC may lead to delayed endotracheal intubation and increased mortality in patients with ARF. ${ }^{29}$ Third, only a portion of patients had lung function data prior to their admission, which was not conducive to exploring the impact of lung function on treatment outcomes. Finally, similar to several studies, ${ }^{1,17,27,30}$ we did not rule out pneumonia cases in this study. Though COPD with pneumonia was one of the common causes of hypercapnic ARF, pneumonia was reported to increase the risk of NIV failure. ${ }^{31}$ In addition to the small number of eligible COPD patients with moderate hypercapnic ARF, we enrolled pneumonia patients partly because the intubation rate of the NIV group in our study was not higher than previous literature reports. ${ }^{32,33}$ However, due to its retrospective design and smaller sample size, well-designed randomized controlled trials examining the use of HFNC in hypercarbic ARF are still warranted.

\section{Conclusions}

Among COPD patients with moderate hypercarbic ARF, the use of HFNC compared with NIV did not result in increased rates of treatment failure. HFNC had better comfort and tolerance than NIV, and is a new potential respiratory support therapy for COPD patients with moderate hypercarbic ARF. 


\section{Abbreviation list}

COPD, Chronic obstructive pulmonary disease; ARF, Acute respiratory failure; NIV, Non-invasive ventilation; HFNC, High-flow nasal cannula oxygen therapy; ICU, Intensive care unit; APACHE II, acute physiological and chronic health status score II; SAPS II, Simplified Acute Physiology Score II. $\mathrm{PaCO}_{2}$, arterial carbon dioxide partial pressure; $\mathrm{PaO}_{2}$, arterial oxygen partial pressure; $\mathrm{FiO}_{2}$, fraction of inspired oxygen.

\section{Availability of data and materials}

The datasets used and/or analysed during the current study are available from the corresponding author in response to reasonable requests.

\section{Acknowledgments}

We would like to thank Dr. Joseph Walline for proofreading assistance and reviewing the final manuscript. This work was supported by Rui E special fund for emergency medicine research (R2017003) and Yangzhou Science and Technology Development Plan (YZ2018090).

\section{Disclosure}

The authors declare that they have no competing interests in this work.

\section{References}

1. Brown H, Dodic S, Goh SS, et al. Factors associated with hospital mortality in critically ill patients with exacerbation of COPD. Int J Chron Obstruct Pulmon Dis. 2018;13:2361-2366. doi:10.2147/ COPD.S168983

2. Shah NM, D'Cruz RF, Murphy PB. Update: non-invasive ventilation in chronic obstructive pulmonary disease. J Thorac Dis. 2018;10 (Suppl 1):S71-s9. doi:10.21037/jtd.2017.10.44

3. Brochard L, Mancebo J, Wysocki M, et al. Noninvasive ventilation for acute exacerbations of chronic obstructive pulmonary disease. $N \mathrm{Engl}$ $J \quad$ Med. 1995;333(13):817-822. doi:10.1056/NEJM19950928 3331301

4. Ischaki E, Pantazopoulos I, Zakynthinos S. Nasal high flow therapy: a novel treatment rather than a more expensive oxygen device. Eur Respir Rev. 2017;26:145. doi:10.1183/16000617.0028-2017

5. Frat JP, Thille AW, Mercat A, et al. High-flow oxygen through nasal cannula in acute hypoxemic respiratory failure. $N$ Engl $\mathrm{J} \mathrm{Med}$. 2015;372(23):2185-2196. doi:10.1056/NEJMoa1503326

6. Hernandez G, Vaquero C, Gonzalez P, et al. Effect of postextubation high-flow nasal cannula vs conventional oxygen therapy on reintubation in low-risk patients: a randomized clinical trial. Jama. 2016;315 (13):1354-1361. doi:10.1001/jama.2016.2711

7. Hernandez G, Vaquero C, Colinas L, et al. Effect of postextubation high-flow nasal cannula vs noninvasive ventilation on reintubation and postextubation respiratory failure in high-risk patients: a randomized clinical trial. Jama. 2016;316(15):1565-1574. doi:10.1001/ jama.2016.14194
8. Braunlich J, Kohler M, Wirtz H. Nasal highflow improves ventilation in patients with COPD. Int $J$ Chron Obstruct Pulmon Dis. 2016;11:1077-1085. doi:10.2147/COPD.S104616

9. Pisani L, Fasano L, Corcione N, et al. Change in pulmonary mechanics and the effect on breathing pattern of high flow oxygen therapy in stable hypercapnic COPD. Thorax. 2017;72(4):373-375. doi:10.1136/thoraxjnl-2016-209673

10. Millar J, Lutton S, O'Connor P. The use of high-flow nasal oxygen therapy in the management of hypercarbic respiratory failure. Ther Adv Respir Dis. 2014;8(2):63-64. doi:10.1177/1753465814521890

11. Pavlov I, Plamondon P, Delisle S. Nasal high-flow therapy for type II respiratory failure in COPD: a report of four cases. Respir Med Case Rep. 2017;20:87-88. doi:10.1016/j.rmcr.2016.12.006

12. Pilcher J, Eastlake L, Richards M, et al. Physiological effects of titrated oxygen via nasal high-flow cannulae in COPD exacerbations: a randomized controlled cross-over trial. Respirology. 2017;22 (6):1149-1155. doi:10.1111/resp. 13050

13. Kim ES, Lee H, Kim SJ, et al. Effectiveness of high-flow nasal cannula oxygen therapy for acute respiratory failure with hypercapnia. J Thorac Dis. 2018;10(2):882-888. doi:10.21037/ jtd.2018.01.125

14. Kim DK, Lee J, Park JH, Yoo KH. What can we apply to manage acute exacerbation of chronic obstructive pulmonary disease with acute respiratory failure? Tuberc Respir Dis (Seoul). 2018;81 (2):99-105. doi:10.4046/trd.2017.0094

15. Berkius J, Sundh J, Nilholm L, Fredrikson M, Walther SM. What determines immediate use of invasive ventilation in patients with COPD? Acta Anaesthesiol Scand. 2013;57(3):312-319. doi:10.1111/ aas. 12049

16. Vogelmeier CF, Criner GJ, Martinez FJ, et al. Global strategy for the diagnosis, management, and prevention of chronic obstructive lung disease 2017 report. GOLD executive summary. Am J Respir Crit Care Med. 2017;195(5):557-582. doi:10.1164/rccm.2017010218PP

17. Lindenauer PK, Stefan MS, Shieh MS, Pekow PS, Rothberg MB, Hill NS. Outcomes associated with invasive and noninvasive ventilation among patients hospitalized with exacerbations of chronic obstructive pulmonary disease. JAMA Intern Med. 2014;174 (12):1982-1993. doi:10.1001/jamainternmed.2014.5430

18. Osadnik CR, Tee VS, Carson-Chahhoud KV, Picot J, Wedzicha JA, Smith BJ. Non-invasive ventilation for the management of acute hypercapnic respiratory failure due to exacerbation of chronic obstructive pulmonary disease. Cochrane Database Syst Rev. 2017;7:Cd004104. doi:10.1002/14651858. CD003881.pub4

19. Stefan MS, Nathanson BH, Higgins TL, et al. Comparative effectiveness of noninvasive and invasive ventilation in critically Ill patients with acute exacerbation of chronic obstructive pulmonary disease. Crit Care Med. 2015;43(7):1386-1394. doi:10.1097/ CCM.0000000000000945

20. Liu J, Duan J, Bai L, Zhou L. Noninvasive ventilation intolerance: characteristics, predictors, and outcomes. Respir Care. 2016;61 (3):277-284. doi:10.4187/respcare.04220

21. Roca O, Hernandez G, Diaz-Lobato S, Carratala JM, Gutierrez RM, Masclans JR. Current evidence for the effectiveness of heated and humidified high flow nasal cannula supportive therapy in adult patients with respiratory failure. Crit Care. 2016;20(1):109. doi:10.1186/s13054-016-1362-x

22. Chatila W, Nugent T, Vance G, Gaughan J, Criner GJ. The effects of high-flow vs low-flow oxygen on exercise in advanced obstructive airways disease. Chest. 2004;126(4):1108-1115. doi:10.1378/ chest.126.4.1108

23. Fricke K, Tatkov S, Domanski U, Franke KJ, Nilius G, Schneider H. Nasal high flow reduces hypercapnia by clearance of anatomical dead space in a COPD patient. Respir Med Case Rep. 2016;19:115-117. doi:10.1016/j.rmcr.2016.08.010 
24. Parke RL, Eccleston ML, McGuinness SP. The effects of flow on airway pressure during nasal high-flow oxygen therapy. Respir Care. 2011;56(8):1151-1155. doi:10.4187/respcare.01106

25. Chanques G, Riboulet F, Molinari N, et al. Comparison of three high flow oxygen therapy delivery devices: a clinical physiological cross-over study. Minerva Anestesiol. 2013;79(12):1344-1355.

26. Moller W, Celik G, Feng S, et al. Nasal high flow clears anatomical dead space in upper airway models. J Appl Physiol. 2015;118 (12):1525-1532. doi:10.1152/japplphysiol.00934.2014

27. Lee MK, Choi J, Park B, et al. High flow nasal cannulae oxygen therapy in acute-moderate hypercapnic respiratory failure. Clin Respir J. 2018;12(6):2046-2056. doi:10.1111/crj.12772

28. Nishimura M. High-flow nasal cannula oxygen therapy in adults: physiological benefits, indication, clinical benefits, and adverse effects. Respir Care. 2016;61(4):529-541. doi:10.4187/respcare.04577

29. Kang BJ, Koh Y, Lim CM, et al. Failure of high-flow nasal cannula therapy may delay intubation and increase mortality. Intensive Care Med. 2015;41(4):623-632. doi:10.1007/s00134-015-3693-5
30. Tsai CL, Lee WY, Delclos GL, Hanania NA, Camargo CA Jr. Comparative effectiveness of noninvasive ventilation vs invasive mechanical ventilation in chronic obstructive pulmonary disease patients with acute respiratory failure. J Hosp Med. 2013;8 (4):165-172. doi:10.1002/jhm.2014

31. Antonelli M, Conti G, Moro ML, et al. Predictors of failure of noninvasive positive pressure ventilation in patients with acute hypoxemic respiratory failure: a multi-center study. Intensive Care Med. 2001;27(11):1718-1728. doi:10.1007/s00134-0011114-4

32. Confalonieri M, Garuti G, Cattaruzza MS, et al. A chart of failure risk for noninvasive ventilation in patients with COPD exacerbation. Eur Respir J. 2005;25:348-355. doi:10.1183/09031936.05.00085304

33. Ozyilmaz E, Ugurlu AO, Nava S. Timing of noninvasive ventilation failure: causes, risk factors, and potential remedies. BMC Pulm Med. 2014;14:19. doi:10.1186/1471-2466-14-19

\section{Publish your work in this journal}

The International Journal of COPD is an international, peer-reviewed journal of therapeutics and pharmacology focusing on concise rapid reporting of clinical studies and reviews in COPD. Special focus is given to the pathophysiological processes underlying the disease, intervention programs, patient focused education, and self management protocols. This journal is indexed on PubMed Central, MedLine and CAS. The manuscript management system is completely online and includes a very quick and fair peer-review system, which is all easy to use. Visit http://www.dovepress.com/testimonials.php to read real quotes from published authors. 